\title{
Collagenolytic activity related to metalloproteases (and serine proteases) in the fish parasite Hysterothylacium aduncum (Nematoda: Anisakidae)
}

\author{
David Malagón ${ }^{1}$, Francisco Javier Adroher ${ }^{1, *}$, Manuel Díaz-López ${ }^{2}$, Rocío Benítez ${ }^{1}$ \\ ${ }^{1}$ Departamento de Parasitología, Facultad de Farmacia, Campus de Cartuja, Universidad de Granada, 18071Granada, Spain \\ ${ }^{2}$ Departamento de Biología Aplicada, Escuela Politécnica Superior, Universidad de Almería, 04071 Almería, Spain
}

\begin{abstract}
Proteases play a vital role in both the life cycle of parasites and the parasite-host relationship and are considered important virulence factors. In the present study, the presence of proteases with collagenolytic activity was investigated in the fish nematode Hysterothylacium aduncum during in vitro development. Collagenolytic activity was found in all studied developmental stages of the nematode (third [L3] and fourth [L4] larval stages and adults). In L3, the activity was maximum at pH 6.5 and, in the other stages, at 7.0. Pepsin is known to favour in vitro development of the worm, but, in this study, collagenolytic activity was shown to be significantly greater when no pepsin was added to the culture medium (at $\mathrm{pH} 6.5, \mathrm{p}=0.011$ ). At $\mathrm{pH} 7.0$, most activity was observed in the immature adult, after the final moult, suggesting that the collagenolytic activity may be involved in remodelling of the cuticle and in sexual maturity. On the other hand, at $\mathrm{pH} 6.5$, activity may be related to tissue migration by L3 within the host. Using specific inhibitors, it was demonstrated that most of the collagenolytic activity detected in all the developmental stages was due to metalloproteases (40 to $100 \%$ ), although serine proteases were also detected in L4 and adults (10 to $30 \%$ ).
\end{abstract}

KEY WORDS: Nematoda · Anisakidae · Anisakidosis · Hysterothylacium aduncum · Fish parasite · Collagenase $\cdot$ Metalloproteases $\cdot$ Serine proteases

\section{INTRODUCTION}

Hysterothylacium aduncum is a parasitic anisakid nematode of crustaceans and fish worldwide, in both fresh- and salt water. Although it does not seem to have any severe consequences for adult fish, González \& Carvajal (1994) have suggested that the stress experienced by the fish may facilitate the development of secondary infections that can prove fatal. Furthermore, in juvenile and larval fish, high mortality may result (Bristow 1990, Balbuena et al. 2000), with a concomitant adverse effect on the economy. In humans, a case of non-invasive anisakidosis caused by an immature female has been described (Yagi et al. 1996), as have cases of food allergy in which the patient showed hypersensitivity to $H$. aduncum antigens (Valero et al. 2003).

The life cycle of an anisakid, such as Hysterothylacium aduncum, is complex. Their definitive hosts tend to be large teleost fish, while crustaceans and smaller fish act as first and second intermediate hosts, respectively (Andersen 1993, Køie 1993). However, numerous paratenic hosts may be involved in this cycle (Klimpel \& Rückert 2005). In our laboratory, we have developed an in vitro culture system that permits the development of the parasite from the third larval stage (L3), collected from an intermediate/paratenic host fish, to mature adult, and in which it is clear that pepsin is necessary for the complete development of the nematode (Iglesias et al. 2002, Adroher et al. 2004). 
Proteases play a very important part in both the life cycle of parasites and the parasite-host relationship and are considered to be important virulence factors. In a previous study, we described the presence of cathepsin-like cysteine proteases in Hysterothylacium aduncum, which may be involved in nutrient digestion and moulting (Malagón et al. 2010). In nematodes, collagenases may be involved in the formation and degradation processes of the cuticle, although they would first need to be activated and secreted (Lee 2002). In Haemonchus contortus a metalloprotease with collagenase activity has been described, which degrades the cuticle sheath isolated from the parasite and is found in the fluid between the new and old cuticles, facilitating escape from the latter during ecdysis in the second moult (Gamble et al. 1989). Other proteases with collagenase activity are also involved in nematode moulting (Page 2001).

L3 Hysterothylacium aduncum migrate from the digestive tract to the mesentery and the peritoneal cavity, and, sometimes, to the muscle tissue of the host (Rello et al. 2008, 2009). Since tissue-migrating parasites use both mechanical and enzymatic processes for host tissue penetration (Karanu et al. 1993), they must have the 'tools' required to degrade the components of the extracellular matrix, as in the case of Strongyloides stercoralis (McKerrow et al. 1990).

To date, collagenases have not been described in Hysterothylacium aduncum. The aim of the present study was to detect collagenolytic activity and observe its variation during the in vitro development of this nematode from L3, recently collected from the intermediate/paratenic host fish, to the mature adult stage.

\section{MATERIALS AND METHODS}

Collection of L3 nematodes and cultivation. L3 Hysterothylacium aduncum were collected from horse mackerel Trachurus trachurus L. purchased at the fish market in Granada (southern Spain). The worms were processed as previously described (Malagón et al. 2009). The larvae were then identified according to morphological features (Yoshinaga et al. 1987, Petter \& Maillard 1988). No molecular techniques were needed, since no cryptic sibling species were detected by Klimpel et al. (2007). Next, a number of larvae were frozen $\left(-80^{\circ} \mathrm{C}\right)$ for enzyme determination (L3-0h). The rest of the larvae were axenized (according to Iglesias et al. 1997) and individually placed in culture at $15^{\circ} \mathrm{C}$, in a modified RPMI-1640 medium with pepsin and foetal bovine serum added (Iglesias et al. 2002).

Preparation of the extract and protein determination. The following samples were taken, washed for $20 \mathrm{~min}$ in $0.9 \% \mathrm{NaCl}$ solution and frozen $\left(-80^{\circ} \mathrm{C}\right)$ for enzyme determination: L3 from fish (L3-0h, 30 larvae $\mathrm{ml}^{-1}$ extract), L3 after $48 \mathrm{~h}$ of cultivation (L3-48h, 25 larvae $\mathrm{ml}^{-1}$ extract), L4 after $14 \mathrm{~d}$ of cultivation (L4, 12 larvae $\mathrm{ml}^{-1}$ extract), immature adult after $21 \mathrm{~d}$ of cultivation (iAdult, 6 worms ml ${ }^{-1}$ extract), and mature adult after $42 \mathrm{~d}$ of cultivation (mAdult, 3 worms $\mathrm{ml}^{-1}$ extract). To determine whether the pepsin in the culture medium affected proteolytic activity, a control was prepared with parasites cultivated without pepsin during the week prior to collection, except L3-48h, which were collected after $48 \mathrm{~h}$ in a culture without pepsin. Worm extract was prepared as described elsewhere (Malagón et al. 2010) and was then centrifuged at $18000 \times g$ for $15 \mathrm{~min}$ at $4^{\circ} \mathrm{C}$; the supernatant was assayed for protein concentration using the Bradford (Bradford 1976) method and stored at $-80^{\circ} \mathrm{C}$.

Enzyme determination. The parasite extracts $(20 \mu \mathrm{l}$ of extract containing $6 \mu \mathrm{g}$ of soluble protein) were diluted to a final volume of $0.2 \mathrm{ml}$ in the following buffers with $\mathrm{pH}$ increments of $0.5 \pm 0.05$ : $50 \mathrm{mM}$ piperazin-1,4-bis(2-ethansulfonic acid) (PIPES): $\mathrm{NaOH}$ (pH 6.0 and 6.5) and $50 \mathrm{mM}$ Tris: $\mathrm{HCl}$ (pH 7.0 to 8.0). Each buffer contained $5 \mathrm{mM} \mathrm{CaCl}_{2}$ and the fluorogenic substrate DQ-collagen Type I from bovine skin (fluorescein conjugate purchased from Molecular ProbesInvitrogen) at a final concentration of $25 \mu \mathrm{g} \mathrm{ml}^{-1} . \mathrm{NaCl}$ is added to buffer, as necessary, in the concentration needed to achieve the ionic strength of a $0.15 \mathrm{M} \mathrm{NaCl}$ solution, taking into account the ions produced by the buffer and the $\mathrm{CaCl}_{2}$. Reactions were incubated at $37^{\circ} \mathrm{C}$ for $100 \mathrm{~min}$ and measured every $2 \mathrm{~min}$. Cleavage of fluorescein conjugate was detected using a fluorimeter with $\lambda$ excitation at $485 \mathrm{~nm}$ and $\lambda$ emission at $538 \mathrm{~nm}$. Control assays were with collagenase Type IV from Clostridium histolyticum (EC 3.4.24.3). Enzyme activity was expressed as fluorescence relative units (FRU) per minute per milligram protein. Preliminary assays were carried out between pH 5.0 and 9.0. Higher activity and substratum stability were shown between $\mathrm{pH} 6.0$ and 8.0.

Inhibition assays. Protease inhibitors were assayed using the fluorogenic substrate DQ-collagen Type I from bovine skin (fluorescein conjugate) by modifications of previously described methods (García-Carreño 1992, Beynon \& Salvesen 2001, Salvesen \& Nagase 2001). Inhibitors were tested at final concentrations of $2 \mathrm{mM}$ (1,10-phenanthroline), $0.05 \mathrm{mM}$ [L-trans-epoxysuccinyl-leucylamide-(4-guanidine)-butane or E64] and $1 \mathrm{mM}$ [4-(2-aminoethyl) benzenesulfonyl fluoride hydrochloride or AEBSF]. Control assays were with papain (EC 3.4.22.2) for E64, $\alpha$-chymotrypsine (EC 3.4.21.1) for AEBSF and collagenase Type IV (EC 3.4.24.3) for 1,10-phenanthroline. The parasite extracts were mixed during $45 \mathrm{~min}$ with the inhibitors prior to adding substrate. As controls, parasite extracts were 
premixed with methanol $0.5 \%$, the solvent for 1,10 phenanthroline (water was the solvent for other inhibitors). Reactions were allowed to proceed, and the protease activity was determined as described above. Inhibition assays were performed at the optimal $\mathrm{pH}$ values for the collagenolytic activity according to worm development stage: $\mathrm{pH} 6.5$ for L3 (L3-0h; L348h) and $\mathrm{pH} 7.0$ for $\mathrm{L} 4$ and immature and mature adults. The effect of inhibitors was expressed as a percentage of inhibition (\%I), determined as: $\% \mathrm{I}=100-$ [(mean $\triangle$ FRU $\mathrm{min}^{-1} \mathrm{mg}^{-1}$ protein in the presence of the inhibitor/mean $\triangle$ FRU $\mathrm{min}^{-1} \mathrm{mg}^{-1}$ protein in the absence of the inhibitor) $\times 100$ ]

Statistical methods. The data were processed using SPSS software (Version 14.0 for Windows). Values were tested for significance by 1- or 2-way ANOVA, depending on variable number; when ANOVA was not applicable, the data were tested using the KruskalWallis (K-W) nonparametric test for ' $k$ ' independent samples. When the data were statistically significant, post hoc multiple comparisons by pairs were performed using Bonferroni's test for the ANOVA or Tamhane's T2 test (for unequal variances) and MannWhitney's U-test with Bonferroni's correction for the Kruskal-Wallis test. The significance level was p < 0.05 .

\section{RESULTS AND DISCUSSION}

Fig. 1 shows the activity of the soluble somatic extract of Hysterothylacium aduncum against DQ-collagen Type I as a function of $\mathrm{pH}$ and development stage of the parasite. Activity was detected in all the stages sampled and at all $\mathrm{pHs}$ within the range studied (6.0 to 8.0). This is the first time that collagenolytic activity has been demonstrated in this nematode. Significant differences were found between parasites cultivated with and without pepsin (2-way ANOVA, p < 0.001), enzymatic activity being greatest in the latter, although the activity profiles were similar throughout. In other nematodes from the same family, such as Anisakis simplex, serine and metalloprotease activity have been demonstrated in their excretion- secretion (ES) products, sufficient to degrade the collagen in the connective tissue of an extracellular matrix (Sakanari $\&$ McKerrow 1990). The connective tissue of the gastrointestinal tract contains collagen Type I, the substrate used in the present study. So, if the parasite secretes enzymes with collagenase activity, it will be able to pass through the extracellular matrix, thus facilitating its passage through the intestinal wall or other tissues and its return to the digestive tract after spending time in the body cavity (Andersen 1993, Iglesias et al. 2002). As a function of $\mathrm{pH}$, the activity profile

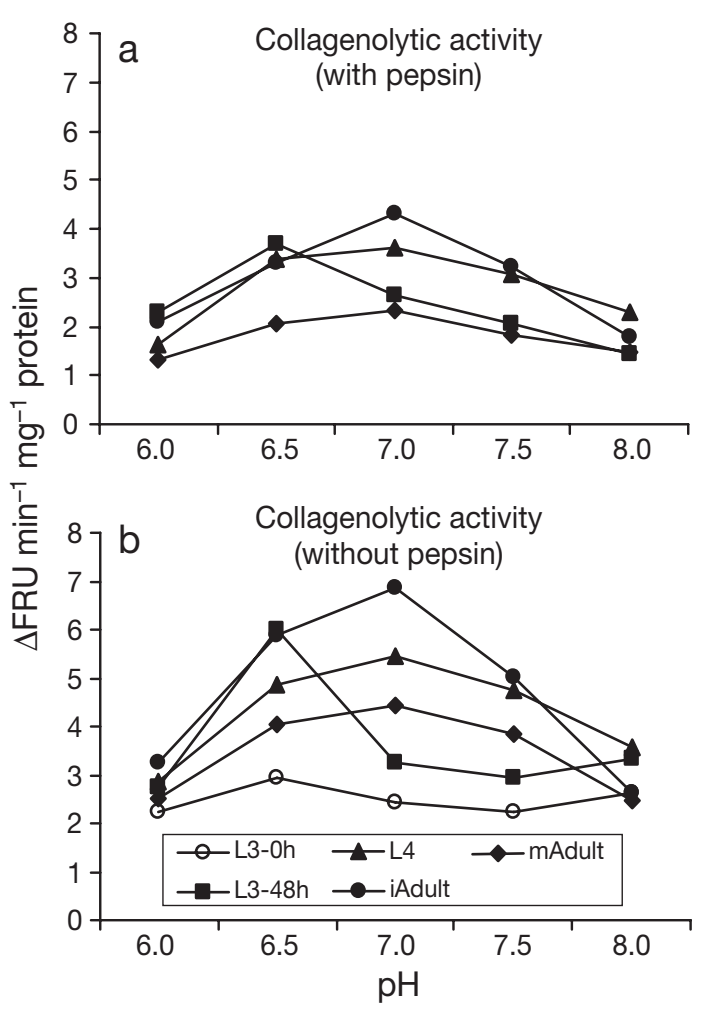

Fig. 1. Hysterothylacium aduncum. pH profile of DQ-collagen Type I cleaving activity in nematodes during in vitro development. The parasites were cultured (a) with or (b) without pepsin as indicated in 'Materials and methods'. Each datapoint is the mean value of 2 to 3 experiments in triplicate. FRU: fluorescence relative units. L3(4): third (fourth)-stage larvae; $0(48) \mathrm{h}$ : after $0(48)$ of cultivation; i(m)Adult: immature (mature) adults

showed at least 2 different activities. In L3 of $H$. aduncum we demonstrated collagenolytic activity with a slightly acidic optimum $\mathrm{pH}$ ( $\mathrm{pH}$ 6.5), while in the other development stages, L4 and adult, the optimum $\mathrm{pH}$ was neutral ( $\mathrm{pH}$ 7.0). This collagenolytic activity could be used by L3 in tissue migration, since it is the only stage of the parasite that migrates through tissues.

Fig. 2 shows activity at optimum pHs in different development stages of the nematode. At pH 6.5, it can be seen that L3, found in the peritoneal cavity of the intermediate/paratenic host fish, showed low activity, which more than doubled after $48 \mathrm{~h}$ in culture without pepsin (L3-48h), decreasing by around $20 \%$ in the next stage (L4), returning to the highest levels in the immature adult stage to then decrease by around $30 \%$ in the mature adult stage. The activity detected in L 4 and the adult stages was probably due to the residual activity of that observed at $\mathrm{pH} 7.0$, as suggested since the activity curves at both pHs were parallel (note peaks in Fig. 1 and small panel in Fig. 2). When activity was measured in worms cultivated with pepsin it decreased from a maximum at L3-48h (25\% greater than in L3) to 


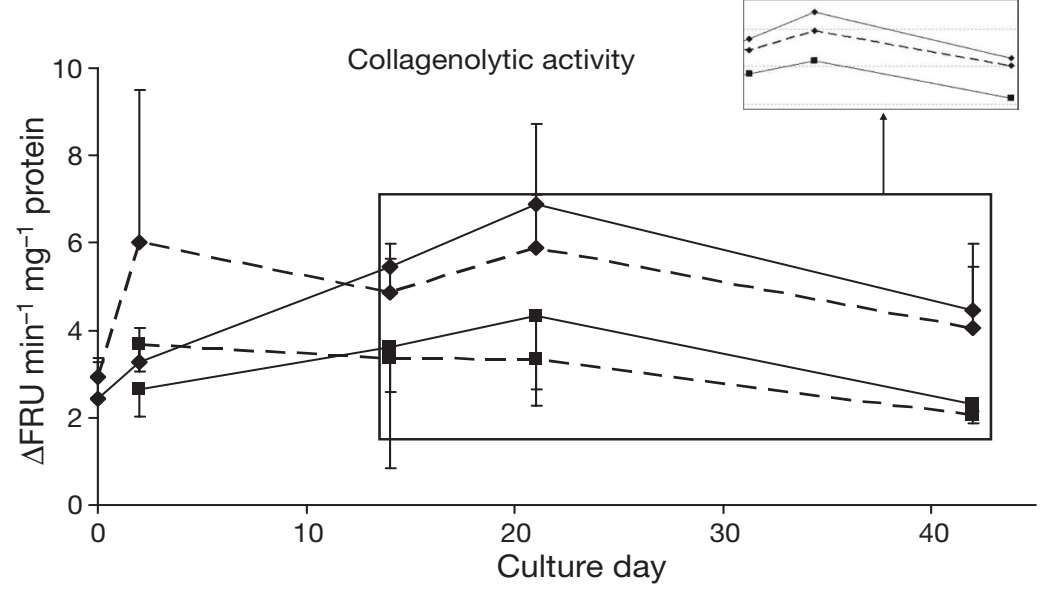

Fig. 2. Hysterothylacium aduncum. Variation of collagenase activity throughout in vitro development of nematodes. Cleaving activity profiles of DQ-collagen Type I at pH 6.5 (dashed lines) and at pH 7.0 (solid lines) with pepsin (ם) and without ( $\bullet$. In order to point out the parallelism between 3 of the 4 curves represented in the box, these 3 curves, without error bars, are shown in the smaller panel. Each datapoint is the mean value of 2 or 3 experiments in triplicate. FRU: fluorescence relative units the worm during ecdysis of M2 has been detected (Rogers \& Brooks 1976, Rogers 1982, Sommerville 1982) and later identified as a metalloprotease (Gamble et al. 1989). Metalloaminopeptidase activity has also been detected in Anisakis simplex, and its involvement in moulting has been suggested (Sakanari \& McKerrow 1990). In the present study, most of the collagenase activity detected in Hysterothylacium aduncum was sensitive to 1,10-phenanthroline, a specific metalloprotease inhibitor (Fig. 3). Total inhibition occurred in L3-48h cultivated with pepsin, but decreased in subsequent development stages, remaining at around $60 \%$. Inhibition was significantly lower for worms cultivated without pepsin (2-way ANOVA, p = 0.002), although with the same profile, being around $80 \%$ in L3 (L3-0h and L3-48h) a minimum in mature adults, where activity was $30 \%$ lower than in L3 parasites recently collected from the host. At pH 6.5, the collagenase activity of the parasites cultivated with pepsin was significantly lower than in those cultivated without pepsin (2-way ANOVA, p = 0.011). The presence of pepsin in the developmental medium of the worm seems to inhibit collagenase expression. So, the absence of pepsin may be a signal for L3 to start to express collagenases after leaving the stomach of the intermediate/paratenic host fish and commencing tissue migration. In fact, pepsin has already been shown to be necessary for development to adult stage in Hysterothylacium aduncum when added to the culture medium at $\mathrm{pH} 4.0$ (Iglesias et al. 2002). Thus, a possible role in vivo may be to inhibit tissue migration, allowing the parasite to continue its development in the gut of the host fish. These changes in the expression and/or activity of metalloproteases with collagenolytic activity and involved in tissue invasion have previously been described in other nematodes such as Strongyloides stercoralis, S. venezuelensis and Ancylostoma caninun (McKerrow et al. 1990, Brindley et al. 1995, Zhan et al. 2002, Maruyama et al. 2006). At pH 7.0 (Fig. 2), it can be seen that the L3-0h showed low activity, increasing to a maximum after the final moult (M4), in immature adults (3-fold that of L3), and then decreasing by $35 \%$ in mature adults. When cultivated with pepsin in the medium the activity profile was parallel but considerably lower (Fig. 2).

Collagenases may also be involved in other processes such as the formation of new and the degradation of old cuticle in nematodes. In Haemonchus contortus a collagenase that attacks the isolated sheaths of

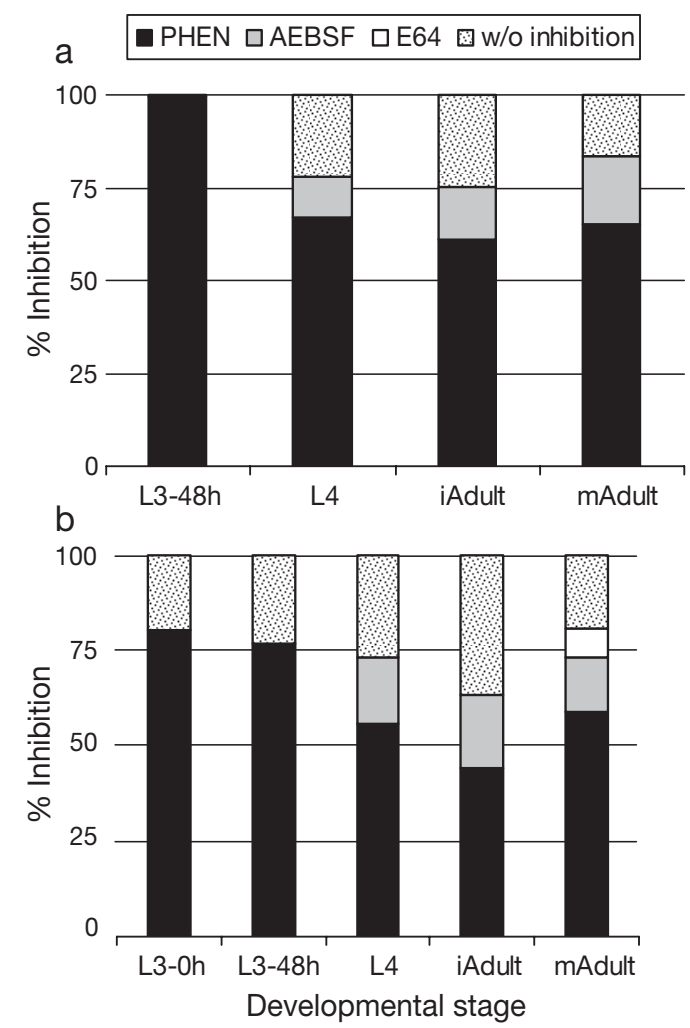

Fig. 3. Hysterothylacium aduncum. Inhibition percentage of optimal DQ-collagen Type I cleaving activity (pH 6.5 in L3-0h and L3-48h; pH 7.0 in L4, iAdult and mAdult) by 1,10phenanthroline (PHEN), 4-(2-aminoethyl) benzenesulfonyl fluoride (AEBSF) and L-trans-epoxysuccinyl-leucylamide-(4guanidine)-butane (E64) in nematodes during in vitro development (see Fig. 1 legend). (a) With pepsin; (b) without pepsin. Values are means of 2 or 3 experiments in triplicate 
and between 40 and $60 \%$ in the subsequent stages. The serine protease activity inhibited by AEBSF showed no significant differences between worms cultivated with pepsin and those without $(\mathrm{K}-\mathrm{W}, \mathrm{p}=0.703)$, did not appear in L3, but was present in the other development stages, showing similar values throughout (between 10 and 20\%). Inhibition of cysteine proteases by E64 was very slight $(<5 \%)$ and only in mature adults cultivated without pepsin. In Angiostrongylus cantonensis, another nematode that needs to pass through the intestinal wall to initiate its migration through the host, collagenolytic activity associated with metallo- and serine proteases released by the worm has been detected (Lee \& Yen 2005). Petralanda et al. (1986), working with infective larvae of Brugia malayi, found high collagenase activity in ES products, but only associated with metalloproteases, although collagenolytic activity was also detected in extracts of adults of this species and of another filarian Onchocerca volvulus. These observations led the authors to suggest a possible role of this enzyme in the migration of filarial worms through tissues and also to maintain the integrity of the cuticle.

In the present study, optimum activity was found at $\mathrm{pH} 6.5$ and 7.0. If the $\mathrm{pH}$ is acidic in the intestinal lumen of the parasite, as has been suggested for other nematodes (Van den Bossche \& Borgers 1973, Williamson et al. 2003, Delcroix et al. 2006), these collagenase activities would probably not take place in the worm's intestine. It would be more likely to take place either in the exterior, in L3, to aid migration through tissues, as in the case of Ancylostoma caninum (Williamson et al. 2003) and/or to act on the cuticle from within the parasite during successive moults. Activity was greater in the medium without pepsin (Figs. 1 \& 2), attaining a maximum in immature adults, coinciding with a period in which the worm doubles in size and must generate cuticle and other structures to support this growth (Yoshinaga et al. 1987, Iglesias et al. 2002). Enzymes have been found in the epidermis of the adult stage of Ascaris suum which are involved in the synthesis of collagen for the cuticle, in spite of there being no further moults (Chvapil et al. 1970). In the present study, the collagenases inhibited by 1,10-phenanthroline, i.e. metalloproteases, showed a decrease in relative activity in the culture medium without pepsin, with a greater percentage of collagenase activity not inhibited by either of the inhibitors employed (Fig. 3). This prompts the hypothesis that the relative scarcity of nutrients of proteinic origin that could be assimilated by the parasite in the medium without pepsin may lead the worm to search for alternatives through the expression of proteases with collagenolytic activity. This has previously been proposed for filarians
(Petralanda et al. 1986), and would tend to compensate for the lack of nutrients caused by the absence of pepsin and/or the products generated by it. In fact, in the free-living nematode Caenorhabditis elegans, the presence of metalloproteases with collagenolytic activity and digestive function has recently been detected (Mohrlen et al. 2003). The modulation of collagenolytic activity at $\mathrm{pH} 7.0$ during the development of Hysterothylacium aduncum may indicate that this activity is directly related to the maturation of the nematode, since, on attaining sexual maturity (mAdult), it showed a notable decrease (Figs. 1 \& 2).

To summarize, 2 collagenase activities with different optimum $\mathrm{pH}$ values were detected, and these were highly sensitive to metalloprotease inhibitors. That found in L3 may be related to the remodelling of the cuticle and with tissue migration within the host, typical of the ascaridoids and other nematodes. The other, found in L4 and adults, may be related to the remodelling of the cuticle during moulting and the growth of the parasite. Further research would be required to characterize these collagenases and to determine their precise role in the life cycle and development of this parasitic nematode and their possible pathological effect on the host fish.

Acknowledgements. This work was funded by the Spanish Grant ACU01-027 from INIA and Research Group BIO-243 from Junta de Andalucía. D. M. is a recipient of a predoctoral fellowship from Consejería de Agricultura y Pesca, Junta de Andalucía (Spain). The English translation was by Mr. Robert Abrahams, BSc.

\section{LITERATURE CITED}

Adroher FJ, Malagón D, Valero A, Benítez R (2004) In vitro development of the fish parasite Hysterothylacium aduncum from the third larval stage recovered from a host to the third larval stage hatched from the egg. Dis Aquat Org 58:41-45

> Andersen K (1993) Hysterothylacium aduncum (Rudolphi, 1862) infection in cod from the Oslofjord: seasonal occurrence of third- and fourth-stage larvae as well as adult worms. Parasitol Res 79:67-72

Balbuena JA, Karlsbakk E, Kvenseth AM, Saksvik M, Nylund A (2000) Growth and migration of third-stage larvae of Hysterothylacium aduncum (Nematoda: Anisakidae) in larval herring Clupea harengus. J Parasitol 86:1271-1275

Beynon RJ, Salvesen G (2001) Commercially available proteinase inhibitors. In: Beynon RJ, Bond JS (eds) Proteolytic enzymes, 2nd edn. A practical approach, Vol 247. Oxford University Press, New York, NY, p 317-330

Bradford MM (1976) Rapid and sensitive method for quantitation of microgram quantities of protein utilizing principle of protein-dye binding. Anal Biochem 72:248-254

Brindley PJ, Gam AA, McKerrow JH, Neva FA (1995) Ss40: the zinc endopeptidase secreted by infective larvae of Strongyloides stercoralis. Exp Parasitol 80:1-7

Bristow GA (1990) Dødelighet hos kveitelarver og yngel i startfôringsfasen. Norsk Fiskeoppdrett 15:40-43 
Chvapil M, Boucek M, Ehrlich E (1970) Differences in the protocollagen hydroxylase activities from Ascaris muscle and hypodermis. Arch Biochem Biophys 140:11-18

Delcroix M, Sajid M, Caffrey CR, Lim KC and others (2006) A multienzyme network functions in intestinal protein digestion by a platyhelminth parasite. J Biol Chem 281: 39316-39329

Gamble HR, Purcell JP, Fetterer RH (1989) Purification of a 44 kilodalton protease which mediates the ecdysis of infective Haemonchus contortus larvae. Mol Biochem Parasitol 33:49-58

García-Carreño FL (1992) Protease inhibition in theory and practice. Biotechnol Educ 3:145-150

González L, Carvajal J (1994) Parásitos en los cultivos marinos de salmónidos en el sur de Chile. Invest Pesq (Chile) 38: 87-96 (with English abstract)

Iglesias L, Valero A, Adroher FJ (1997) Some factors which influence the in vitro maintenance of Anisakis simplex (Nematoda). Folia Parasitol (Praha) 44:297-301

Iglesias L, Valero A, Gálvez L, Benítez R, Adroher FJ (2002) In vitro cultivation of Hysterothylacium aduncum (Nematoda: Anisakidae) from 3rd-stage larvae to egg-laying adults. Parasitology 125:467-475

Karanu FN, Rurangirwa FR, McGuire TC, Jasmer DP (1993) Haemonchus contortus: identification of proteases with diverse characteristics in adult worm excretory-secretory products. Exp Parasitol 77:362-371

Klimpel S, Rückert S (2005) Life cycle strategy of Hysterothylacium aduncum to become the most abundant anisakid fish nematode in the North Sea. Parasitol Res 97:141-149 (Erratum on p 340-343)

Klimpel S, Kleinertz S, Hanel R, Rückert S (2007) Genetic variability in Hysterothylacium aduncum, a raphidascarid nematode isolated from sprat (Sprattus sprattus) of different geographical areas of the northeastern Atlantic. Parasitol Res 101:1425-1430

Køie M (1993) Aspects of the life cycle and morphology of Hysterothylacium aduncum (Rudolphi, 1802) (Nematoda, Ascaridoidea, Anisakidae). Can J Zool 71:1289-1296

Lee DL (2002) Cuticle, moulting and exsheathment. In: Lee DL (ed) The biology of nematodes. Taylor Francis, Florence, KY, p 171-209

Lee JD, Yen CM (2005) Protease secreted by the infective larvae of Angiostrongylus cantonensis and its role in the penetration of mouse intestine. Am J Trop Med Hyg 72: 831-836

Malagón D, Benítez R, Valero A, Adroher FJ (2009) $\mathrm{CO}_{2}$-fixing enzymes and phosphoenolpyruvate metabolism in the fish parasite Hysterothylacium aduncum (Ascaridoidea, Anisakidae). Dis Aquat Org 85:217-223

Malagón D, Díaz-López M, Benítez R, Adroher FJ (2010) Cathepsin B- and L-like cysteine protease activities during the in vitro development of Hysterothylacium aduncum (Nematoda: Anisakidae), a worldwide fish parasite. Parasitol Int 59:89-92

Maruyama H, Nishimaki A, Takuma Y, Kurimoto M and others (2006) Successive changes in tissue migration capacity of developing larvae of an intestinal nematode, Strongyloides venezuelensis. Parasitology 132: 411-418

McKerrow JH, Brindley P, Brown M, Gam AA, Staunton C, Neva FA (1990) Strongyloides stercoralis: identification of

Editorial responsibility: Alex Hyatt, Geelong, Victoria, Australia a protease that facilitates penetration of skin by the infective larvae. Exp Parasitol 70:134-143

Mohrlen F, Hutter H, Zwilling R (2003) The astacin protein family in Caenorhabditis elegans. Eur J Biochem 270: $4909-4920$

Page AP (2001) The nematode cuticle: synthesis, modification and mutants. In: Kennedy MW, Harnett W (eds) Parasitic nematodes: molecular biology, biochemistry and immunology. CABI Publishing, Wallingford, p 167-194

Petralanda I, Yarzabal L, Piessens WF (1986) Studies on a filarial antigen with collagenase activity. Mol Biochem Parasitol 19:51-59

Petter AJ, Maillard C (1988) Larves d'ascarides parasites de poissons en Méditerranée occidentale. Bull Mus Natl Hist Nat, 4 10A:347-369 (with English abstract)

$>$ Rello FJ, Adroher FJ, Valero A (2008) Hysterothylacium aduncum, the only anisakid parasite of sardines (Sardina pilchardus) from the southern and eastern coasts of Spain. Parasitol Res 104:117-121

Rello FJ, Valero A, Benítez R, Adroher FJ (2009) The fishing area as a possible indicator of the infection by anisakids in anchovies (Engraulis encrasicolus) from southwestern Europe. Int J Food Microbiol 129:277-281

Rogers WP (1982) Enzymes in the exsheathing fluid of nematodes and their biological significance. Int $\mathrm{J}$ Parasitol 12: 495-502

> Rogers WP, Brooks F (1976) Zinc as a co-factor for an enzyme involved in exsheathment of Haemonchus contortus. Int $\mathrm{J}$ Parasitol 6:315-319

Sakanari JA, McKerrow JH (1990) Identification of the secreted neutral proteases from Anisakis simplex. J Parasitol 76:625-630

Salvesen G, Nagase H (2001) Inhibition of proteolytic enzymes. In: Beynon RJ, Bond JS (eds) Proteolytic enzymes, 2nd edn. A practical approach, Vol 247. Oxford University Press, New York, NY, p 105-130

Sommerville RI (1982) The mechanics of moulting in nematodes. In: Meerovitch E (ed) Aspects of parasitology. Institute of Parasitology, McGill University, Montreal, p 407-433

> Valero A, Terrados S, Díaz V, Reguera V, Lozano J (2003) Determination of IgE in the serum of patients with allergic reactions to four species of fish-parasite anisakids. J Investig Allergol Clin Immunol 13:94-98

> Van den Bossche H, Borgers M (1973) Subcellular distribution of digestive enzyme in Ascaris suum intestine. Int J Parasitol 3:59-65

Williamson AL, Brindley PJ, Knox DP, Hotez PJ, Loukas A (2003) Digestive proteases of blood-feeding nematodes. Trends Parasitol 19:417-423

Yagi $K$, Nagasawa $K$, Ishikura $H$, Nakagawa A, Sato N, Kikuchi K, Ishikura H (1996) Female worm Hysterothylacium aduncum excreted from human: a case report. Jpn J Parasitol 45:12-23

Yoshinaga T, Ogawa K, Wakabayashi H (1987) Experimental life cycle of Hysterothylacium aduncum (Nematoda: Anisakidae) in fresh water. Fish Pathol 22:243-251

Zhan B, Hotez PJ, Wang Y, Hawdon JM (2002) A developmentally regulated metalloprotease secreted by host-stimulated Ancylostoma caninum third-stage infective larvae is a member of the astacin family of proteases. Mol Biochem Parasitol 120:291-296

Submitted: October 27, 2009; Accepted: April 27, 2010

Proofs received from author(s): June 4, 2010 